\title{
Analysis of Dynamic Performance for Multiple Dividing Wall Distillation Columns
}

\author{
Fernando Israel Gómez-Castro, ${ }^{\dagger} * *$ Mario Alberto Rodríguez-Ángeles, ${ }^{\dagger,+}$
}

Juan Gabriel Segovia-Hernández, ${ }^{\dagger}$ Salvador Hernández, ${ }^{\dagger}$ Claudia Gutiérrez-Antonio, ${ }^{\S}$

Abel Briones-Ramírez," and Agustín Ramón Uribe Ramírez ${ }^{\dagger}$

${ }^{\dagger}$ Universidad de Guanajuato, Campus Guanajuato, División de Ciencias Naturales y Exactas, Departamento de Ingeniería Química, Noria Alta S/N Col. Noria Alta, Guanajuato, Guanajuato, México 36050

${ }^{\ddagger}$ Instituto Tecnológico Sanmiguelense, Calle Escuadrón 201 No. 10, Palmita de Landeta Km. 0.5, Carretera San Miguel-Dr. Mora, San Miguel de Allende, Guanajuato, México 37748

${ }^{\S}$ CIATEQ A.C., Av. Manantiales 23A Parque Industrial Bernardo Quintana, El Marqués, Querétaro, México 76000

"Exxerpro Solutions, Av. del Sol 1B Local 4B, Plaza Comercial El Sol, Col. El Sol, Querétaro, Querétaro, México 76113

ABSTRACT: Dividing wall columns are intensified process equipment with the capacity of reducing both capital and operational costs for a given vapor-liquid separation, when compared with conventional distillation sequences. For some kinds of mixtures, distillation systems with two dividing walls have been theoretically proved to present lower energy requirements and lower total annual costs than systems with a single dividing wall. Nevertheless, the use of an additional wall may lead to operational issues on the column, because of the more complex arrangement of the walls on the trays of the columns, where additional split of the vapor and liquid streams is expected. Thus, in this work the open-loop properties (minimum singular value and condition number) for the double dividing wall column are studied and compared with those of the dividing wall column for a wide range of frequencies, in order to determinate if the use of additional dividing walls may lead to potential control problems. It has been found that both systems show similar dynamic performance, with advantages for the double dividing wall column for mixtures with low composition of the middle-boiling component.

\section{INTRODUCTION}

Distillation is one of the most used separation methods in the chemical industry, mainly because of its relative simplicity and the existent knowledge about its design and performance. The main disadvantage of this separation process relies on its high energy requirements to achieve the desired purification. The costs related with satisfying such energy requirements represent the higher contribution to the total annual cost of a distillation column. ${ }^{1}$ In order to reduce energy requirements in distillation sequences, complex structures, known as thermally coupled distillation sequences, have been developed. Thermally coupled sequences take advantage of the zones with a maximum on the composition of the middle-boiling component, using vapor and liquid interconnection streams, which allows heat transfer by direct contact between the internal streams of the columns, then reducing the required number of condensers and/or reboilers. For proper flow rates of the interlinking streams, these systems can produce important energy savings when compared with conventional distillation sequences. Among the thermally coupled distillation sequences for ternary mixtures, one of the most studied systems is known as the Petlyuk column. ${ }^{2-5}$ It has been reported that this distillation system allows energy savings up to $50 \%$ over conventional schemes. ${ }^{6-8}$ Nevertheless, the Petlyuk column shows operational issues due to the differences in the pressure profiles between the prefractionator and the main column. Thus, for its practical implementation, a thermodynamically equivalent system is used, known as a dividing wall column (DWC, Figure 1a). Dividing wall columns maintain the low energy requirements of the Petlyuk column, and additionally, the a)
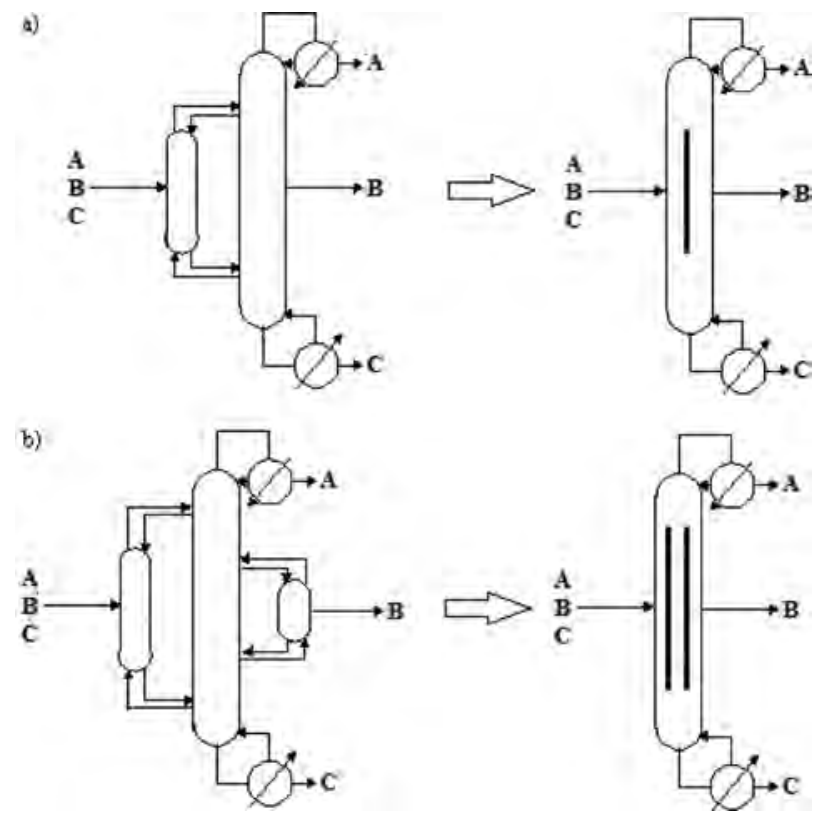

Figure 1. Dividing wall systems and their thermodynamically equivalent Petlyuk-like columns: (a) single dividing wall column; (b) double dividing wall column.

Received: April 26, 2013

Revised: June 4, 2013

Accepted: June 12, 2013

Published: June 12, 2013 
Table 1. Mixtures under Analysis

\begin{tabular}{cclc} 
mixture & \multicolumn{1}{c}{ components } & feed composition & $\begin{array}{c}\text { base purity } \\
\text { (top/side/bottom) }\end{array}$ \\
M1 & $\begin{array}{c}n \text {-pentane, } n \text {-hexane, } \\
n \text {-heptane }\end{array}$ & $0.40 / 0.20 / 0.40$ & $0.987 / 0.98 / 0.986$ \\
M2 & $\begin{array}{c}\text { methyl formate, } \\
\text { methanol, } \\
n \text {-butanol }\end{array}$ & $0.06 / 0.913 / 0.027$ & $0.986 / 0.9997 / 0.983$ \\
& & & \\
\hline
\end{tabular}

Table 2. Design Variables for Selected Cases from Pareto Front

\begin{tabular}{llllc} 
& M1, DWC & \multicolumn{1}{c}{$\begin{array}{c}\text { M1, } \\
\text { DDWC }\end{array}$} & M2, DWC & $\begin{array}{c}\text { M2, } \\
\text { DDWC }\end{array}$ \\
$\begin{array}{l}\text { no. stages (main } \\
\text { column) }\end{array}$ & 51 & 45 & 59 & 57 \\
$\begin{array}{c}\text { stages for } \\
\text { prefractionator } \\
\begin{array}{c}\text { stages for } \\
\text { postfractionator }\end{array}\end{array}$ & $14-27$ & $13-26$ & $28-39$ & $37-43$ \\
$\begin{array}{c}\text { reflux ratio } \\
\text { heat duty (kJ/h) }\end{array}$ & $8,592,029$ & $2,658,030$ & $4,301,501$ & $5,216,773$ \\
$\begin{array}{c}\text { interlinking liquid } \\
\text { flow rate (kmol/h) }\end{array}$ & 21.9 & $17.0 / 27.4$ & 5.1 & $8.8 / 123.9$ \\
$\begin{array}{c}\text { interlinking vapor } \\
\text { flow rate (kmol/h) }\end{array}$ & 33.8 & $31.5 / 20.9$ & 33.9 & $47.9 / 96.5$ \\
$\begin{array}{c}\text { side stream flow rate } \\
\quad(\mathrm{kmol} / \mathrm{h})\end{array}$ & 8.7 & 8.7 & 91.2 & 91.2 \\
\hline
\end{tabular}

DWC presents lower capital costs (since the separation occurs in a single shell), due to less plot area, shorter piping, and less electrical runs being required; furthermore, a smaller flare system is necessary because of the lower heat input and smaller fire-case surface. ${ }^{9}$ It has been reported that, by isolating the dividing wall, additional energy savings of $10 \%$ can be achieved. ${ }^{10}$ The use of dividing wall columns in the industry has been growing in the last few years, with BASF AG, M.W. Kellog, Sasol, and other companies as their main users. ${ }^{11,12}$

As a way to further reduce the energy requirements for the separation of ternary mixtures, allowing a better match in the compositions of the interlinking stages of the DWC, $\mathrm{Kim}^{13}$ has proposed an alternative scheme; this scheme implies the use of two dividing walls in a single shell (DDWC), which thermodynamically equivalent system is a Petlyuk-like system with a prefractionator and a postfractionator (Figure $1 \mathrm{~b}$ ). Gómez-Castro et al. ${ }^{14,15}$ have reported the steady-state analysis of DWC and DDWC, by using stochastic optimization methods for the design and optimization of the distillation schemes. The authors report that the DDWC shows lower energy requirements than the DWC, for a mixture with a low concentration of the middle-boiling component. Ruiz-Marin et al. ${ }^{16}$ report that the use of a posfractionator (i.e., the second dividing wall) provides improvement over the Petlyuk column only for mixtures with an ESI value lower than 1 . Gómez-Castro et al. ${ }^{15}$ present a Pareto front of optimal solutions to the design and optimization problem of DWC and DDWC, reporting a strategy for the calculation of the required diameter for the DDWC, based on the distribution of the vapor flows. Olujic et al. ${ }^{17}$ presented a strategy for dimensioning multiple dividing wall columns for the separation of mixtures with four components.

An important characteristic of any process equipment is its dynamic performance. In terms of operability, a system which better absorbs the possible perturbations on its variables is preferable, because a lower control effort is required to stabilize it into its set point or to change it to a new set point. For the DWC, (a)

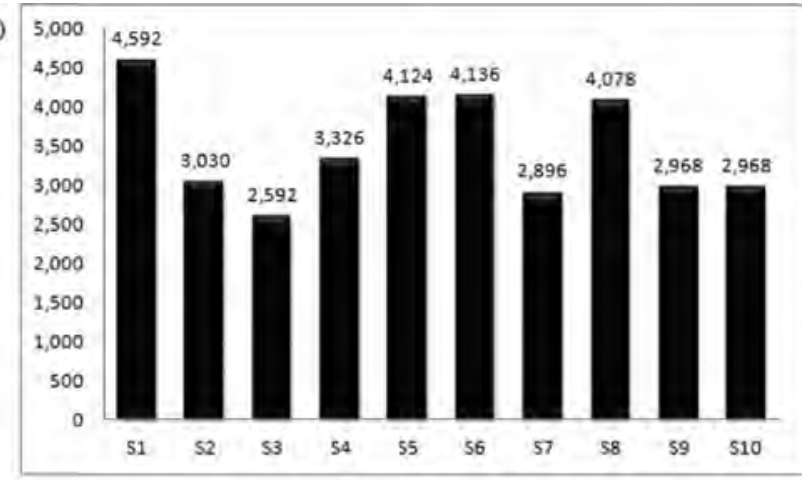

(b)

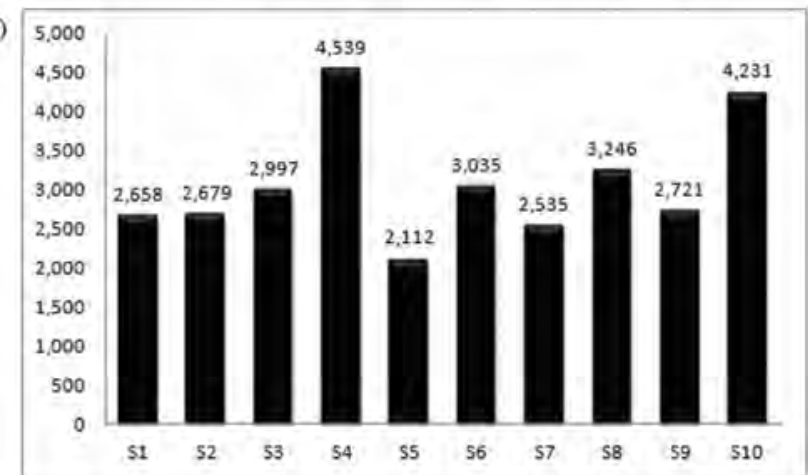

(c)

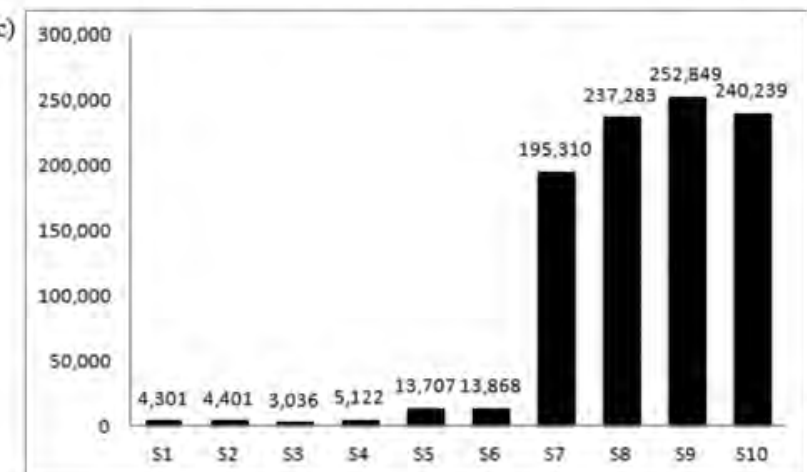

(d)

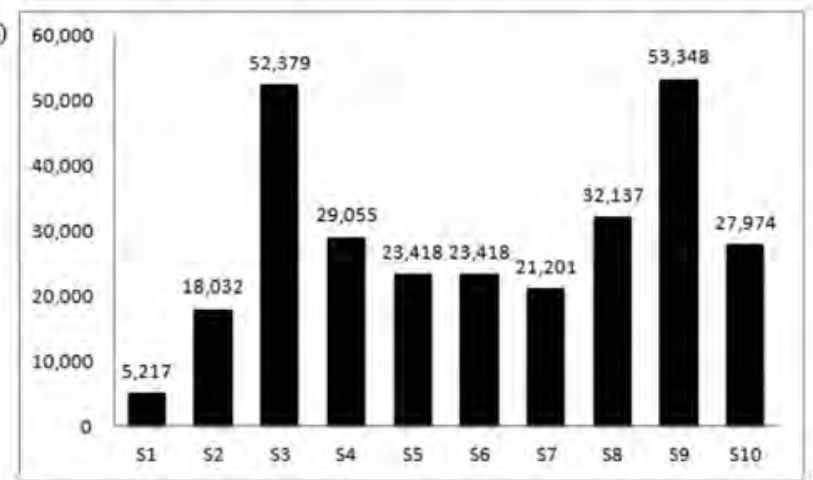

Figure 2. Energy requirements for the selected cases, with $Q$ in $M J / h$ : (a) M1, DWC; (b) M1, DDWC; (c) M2, DWC; (d) M2, DDWC.

there are many studies dealing with the analysis of the dynamic response for such a thermally coupled system. Contrary to what may be inferred from the complex structure of the DWC system, it has been proved that the controllability of the DWC does not differ considerably and can be even better than that of conventional distillation sequences. ${ }^{18-21}$ Halvorsen and Skogestad ${ }^{22}$ established five manipulated variables for a DWC, which are the reflux ratio, the reboiler duty, the side stream flow rate, and the interlinking vapor and liquid flow rates, translated as the splits for 
Table 3. Matrix of Transfer Functions for DWC, Case S1 (M1)

$$
G(s)=\left[\begin{array}{cccc}
R & S & 0 \\
\frac{0.0464}{0.7782 s+1} & \frac{0.0464}{0.7778 s+1} & \frac{0.0088}{0.3536 s+1}-\frac{0.0036}{1.0424 s+1} \\
\frac{2.8356}{1.0986 s^{2}+1.6298 s+1} & \frac{-0.0016}{0.7502 s+1} & \frac{-315.8744}{0.4598 s+1} \\
\frac{-0.0468}{0.9037 s+1} & \frac{-0.0468}{0.9037 s+1} & \frac{5.5924}{0.0695 s+1}
\end{array}\right] \text { NC5 }
$$

Table 4. Matrix of Transfer Functions for DDWC, Case S1 (M1)

$$
G(s)=\left[\begin{array}{ccc}
\mathrm{R} & \mathrm{S} & \mathrm{Q} \\
\frac{5.1624}{1.2831 s+1} & \frac{0.0668}{2.1864 s+1} & \frac{-6.9592}{0.9968 s+1}-\frac{0.7368}{2.0552 s+1} \\
\frac{-1.2432}{18.1779 s+1} & \frac{-0.0088}{0.2274 s+1} & \frac{-0.9588}{27.8728 s+1} \\
\frac{-6.3736}{1.1709 s+1}-\frac{0.9548}{2.3915 s+1} & \frac{0.8548}{1.5926 s+1} & \frac{5.6052}{1.7916 s+1}
\end{array}\right]_{\text {NC7 }}^{\text {NC5 }} \text { NC6 }
$$

(a)

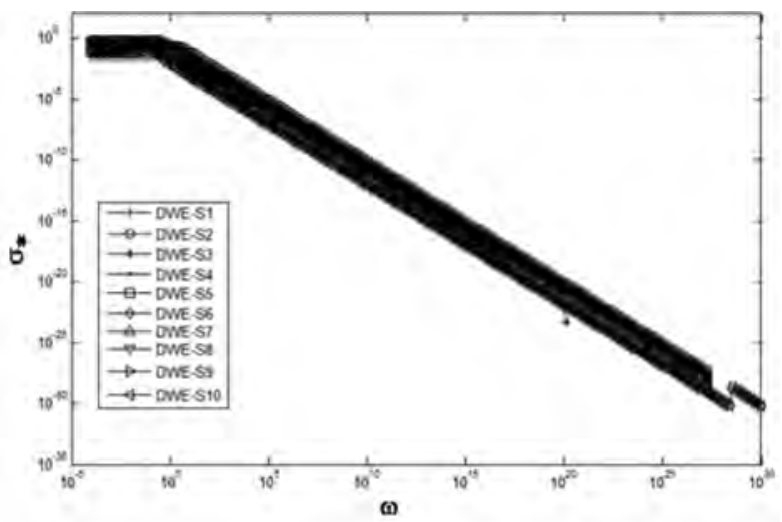

(b)

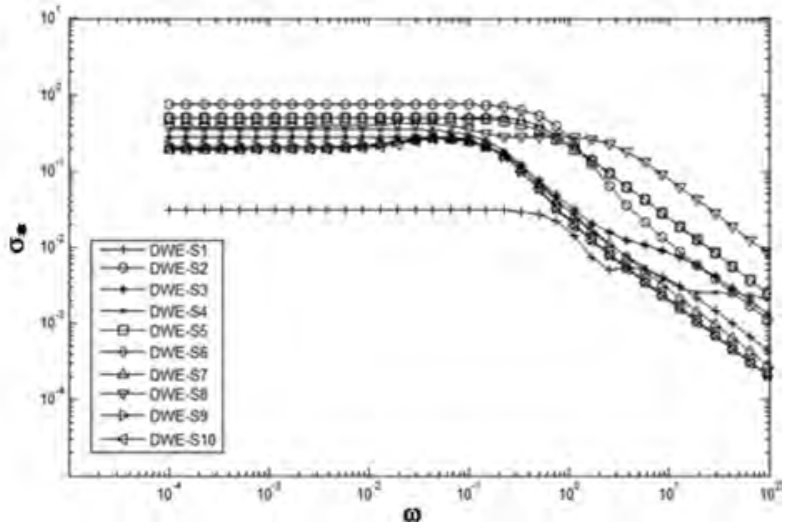

Figure 3. (a) Minimum singular value for DWC, M1; (b) zoom-in to the low frequency region.

both interlinking streams. Serra et $\mathrm{al}^{23}$ reported that the controllability of the DWC may be improved when working at a point out of the optimal steady-state condition. For the closedloop control of DWC, different alternative schemes have been proposed, ${ }^{24-32}$ mainly varying the coupled pairs of manipulated/ controlled variables. In a recent study, Niggemann et al. ${ }^{33}$ presented a model for the analysis of the start-up of dividing wall columns. Model predictive control has also been used for dividing wall columns. ${ }^{34}$ Martinez-Cisneros et al. ${ }^{35}$ presented an (a)

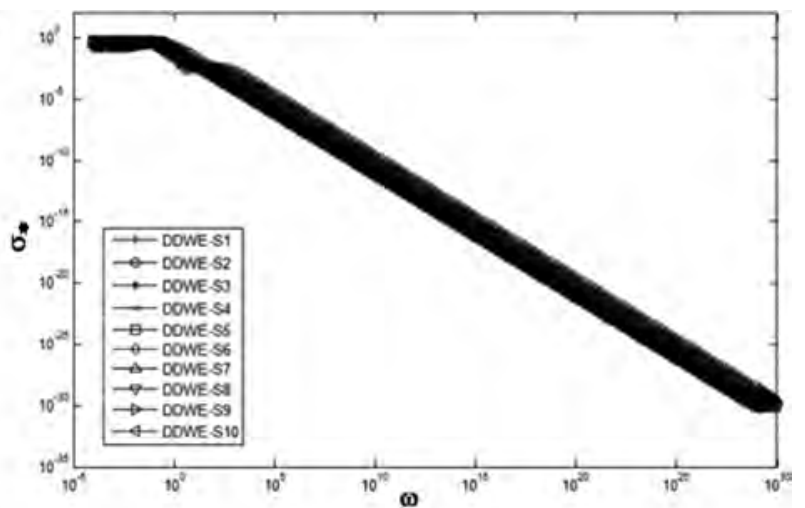

(b)

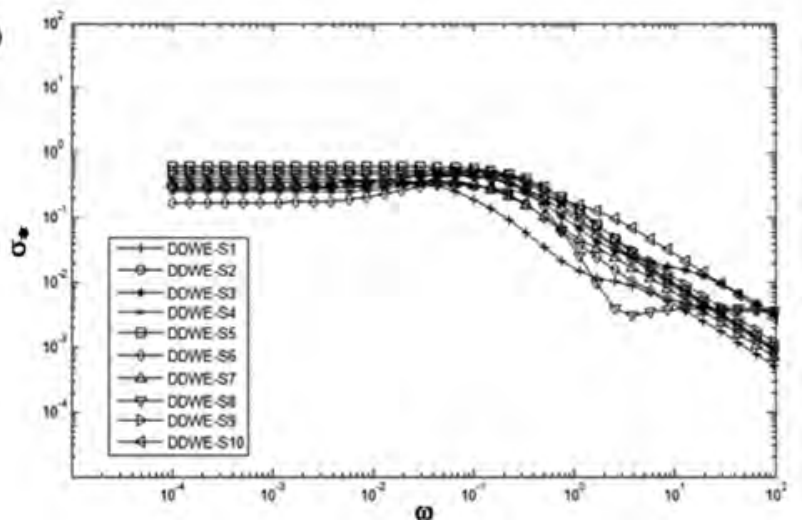

Figure 4. (a) Minimum singular value for DDWC, M1; (b) zoom-in to the low frequency region.

analysis of the dynamic properties for alternative schemes to the Petlyuk column, including a Petlyuk-like system with a postfractionator. They report that the system with a postfractionator presents better open-loop properties than the Petlyuk column, together with low values for the integral absolute error (IAE) when analyzed in a closed-loop study. Almost all the aforementioned works deal with the controllability of the dividing wall column. Nevertheless, to the authors' knowledge, there are only a few works reporting the effect of 

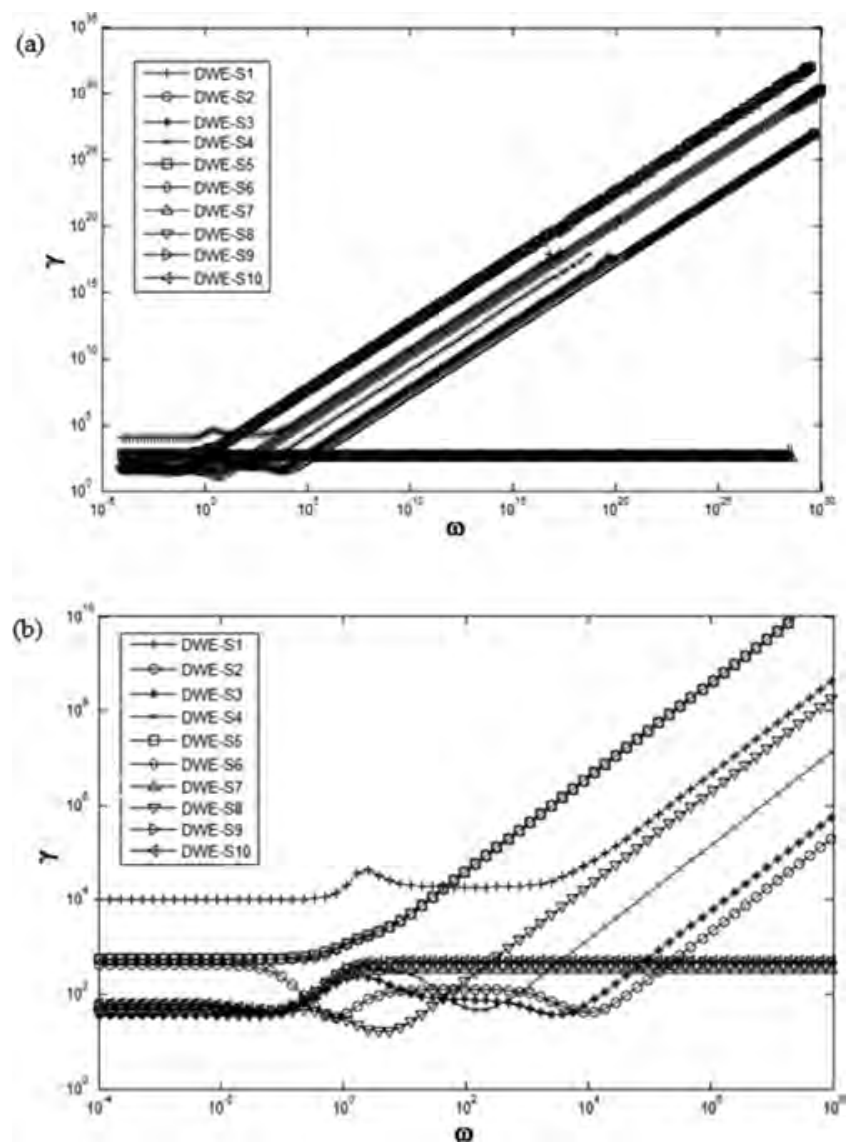

Figure 5. (a) Condition number for DWC, M1; (b) zoom-in to the low frequency region.

using multiple dividing walls on the dynamic properties of the dividing wall columns. ${ }^{14,35}$ In these previous works, just a single design for each separation alternative is analyzed.

In this paper, an open-loop analysis is presented for both dividing wall systems, aiming to determine dynamic properties (minimum singular value and condition number) which may be helpful to predict potential controllability problems of the studied systems. The analysis is applied to a set of different Pareto points (optimal designs) for each system (DWC and DDWC), allowing evaluation of the dynamic properties in designs with different compromises between the optimization variables. According to the results, DWC and DDWC show similar dynamic performances when low frequency regions are considered. Nevertheless, for high frequencies, DDWC has better open-loop properties when mixtures with low quantities of the middle-boiling component are separated. When a mixture with high quantities of the middle-boiling component is analyzed, DWC shows better open-loop properties than the DDWC.

\section{ANALYSIS OF DYNAMIC PROPERTIES}

Singular value decomposition (SVD) has been used as a tool to determine dynamic properties for the systems under analysis. To perform such a study, open-loop responses to perturbations on the main variables of the columns are obtained by using Aspen Dynamics. To do this analysis, steady-state simulations were exported to Aspen Dynamics as flow-driven simulations. Then, manipulated variables are perturbed, one at a time, by $5 \%$ of the steady-state value, and the responses of the measured variables (a)
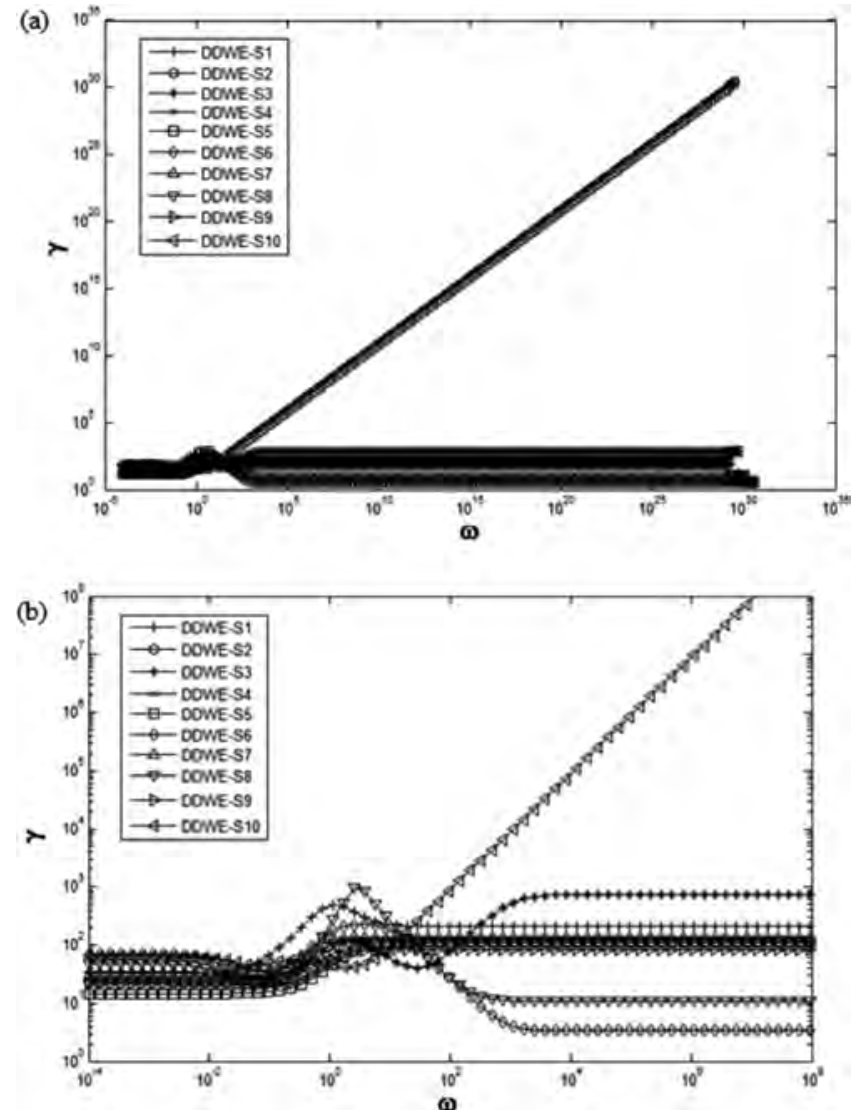

Figure 6. (a) Condition number for DDWC, M1; (b) zoom-in to the low frequency region.

are obtained until a new steady-state is achieved for all those variables. This procedure is repeated for all the manipulated variables. For both schemes, DWC and DDWC, the measured and manipulated variables are the same: reflux ratio, side stream flow rate, and reboiler duty as manipulated variables; and purity of top product, purity of side product, and purity of bottom product, respectively, as measured variables. Once the dynamic responses have been obtained, they are adjusted to transfer functions and ordered in a matrix; then, SVD is applied to the resultant matrix of transfer functions for each case under study, programming the matrix in MATLAB and using the SVD tool available in the same software. SVD is a technique in which a matrix $\mathbf{G}$ is separated in three different matrixes $\mathbf{V} \boldsymbol{\Sigma} \mathbf{W}^{\mathbf{H}}$, where $\mathbf{V}$ is a matrix of left singular vectors, $\mathbf{W}^{\mathrm{H}}$ is a matrix of right singular vectors, and $\boldsymbol{\Sigma}$ is the matrix of singular values. The elements on the diagonal of $\boldsymbol{\Sigma}$ are scalar, known as singular values. The lower of the singular values is known as the minimum singular value $\left(\sigma^{*}\right)$, and it is a measurement of the potential difficulties which may show a dynamic system when a closed-loop feedback control system is implemented. Another important value obtained from SVD is the condition number, $\gamma$, which is defined as follows:

$$
\gamma=\sigma^{*} / \sigma
$$

where $\sigma^{*}$ is the highest of the singular values. Condition number is a measurement of the sensibility of the system to uncertainties on the parameter of the model. Minimum singular value and condition number are useful values for comparison between different dynamic systems, since the scheme with the highest minimum singular value and the lowest condition number is expected to show better closed-loop properties among the compared alternatives. 
(a)

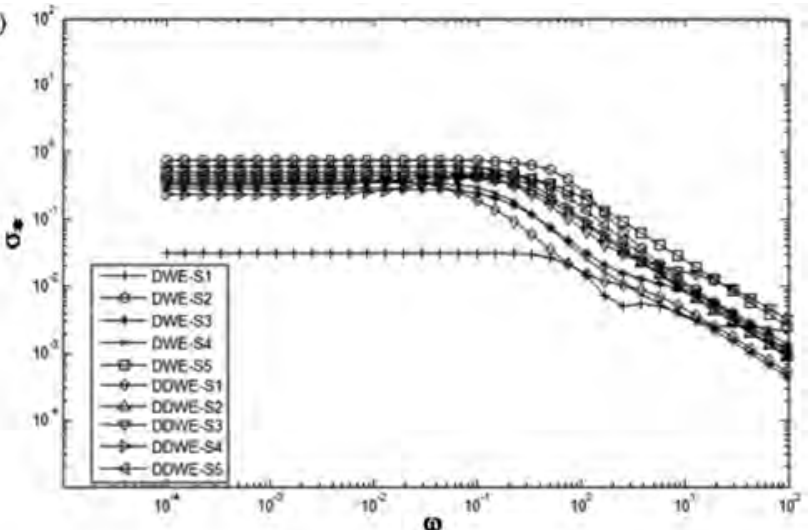

(b)

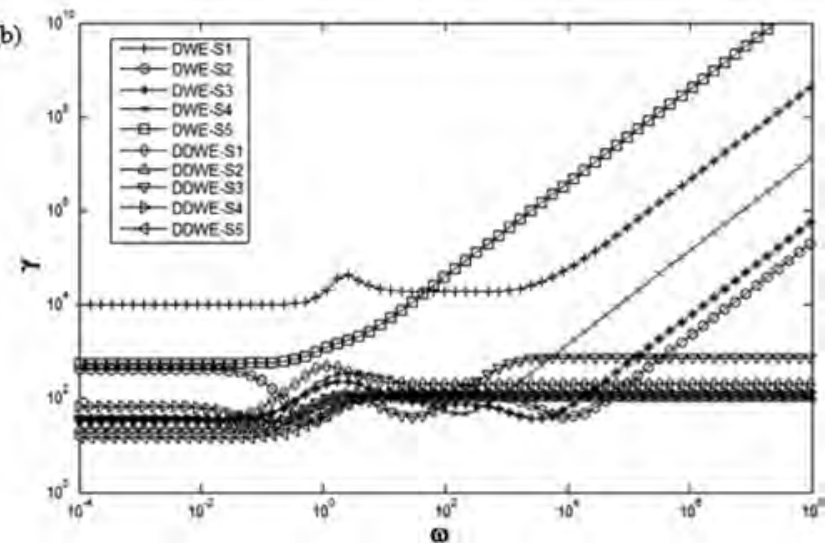

Figure 7. Comparison between dynamic properties of DWC and DDWC (M1): (a) Minimum singular value; (b) Condition number.

\section{CASE OF STUDY}

The separation of two ternary mixtures in DWC and DDWC schemes is considered. The analyzed mixtures are taken from a previous work ${ }^{15}$ and are presented in Table 1. Mixture M1 consists of a hydrocarbon mixture with a low composition of the middle-boiling component. Mixture M2 consists of an alcohol mixture with a very high composition of the middle-boiling component. The molar feed flow rate is $45.35 \mathrm{kmol} / \mathrm{h}$ for mixture $\mathrm{M} 1$ and $100 \mathrm{kmol} / \mathrm{h}$ for mixture M2. The designs considered for this study have been previously obtained by a genetic algorithm linked to the process simulator Aspen Plus. To obtain a quicker convergence of the optimization algorithm, artificial neural networks have been used. For further details of the design and optimization methodology, please consult the work of GómezCastro et al. ${ }^{15}$ The open-loop analysis considers the ten designs from the Pareto fronts with the lower energy requirements from the work of Gomez-Castro et al., ${ }^{15}$ identified in this work as S1 (the first design appearing in the Pareto front), S2 (the second design appearing in the Pareto front), and so on. For illustrative purposes, in Table 2 the design parameters for the S1 designs for each Pareto front are shown. Energy requirements for all the studied systems are presented in Figure 2. A considerable dispersion can be observed for the mixture M2, because of the difficulty to separate a mixture with such a high composition of the middle-boiling component.

\section{RESULTS}

Results for the open-loop analysis will be presented in this section. As an example of transfer function matrices, Tables 3 and 4 show such matrices for the cases S1 of DWC and DDWC, (a)

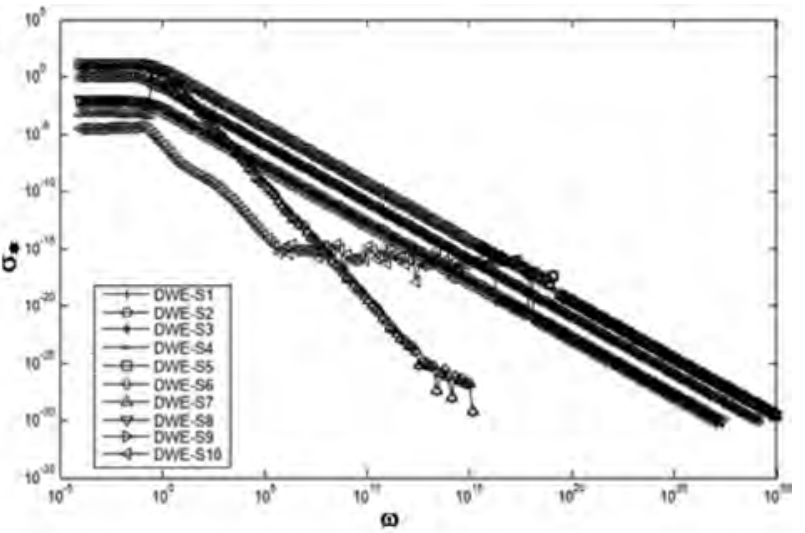

(b)

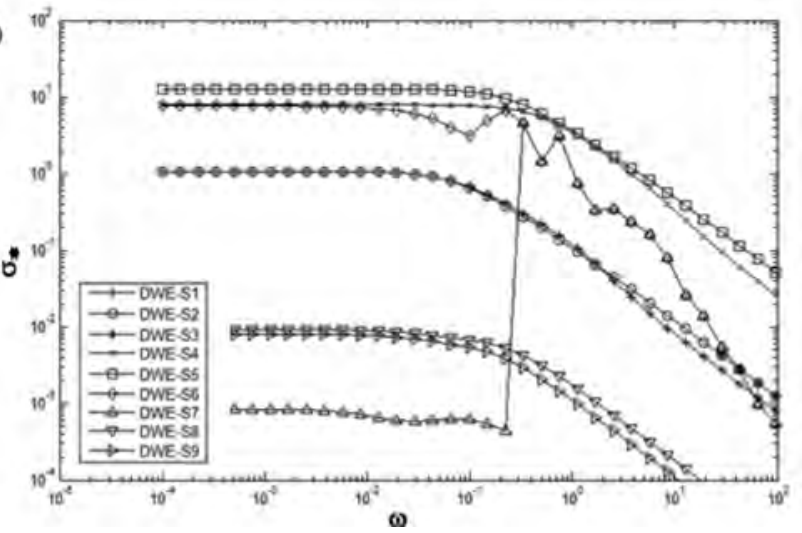

Figure 8. (a) Minimum singular value for DWC, M2; (b) zoom-in to the low frequency region.

(a)

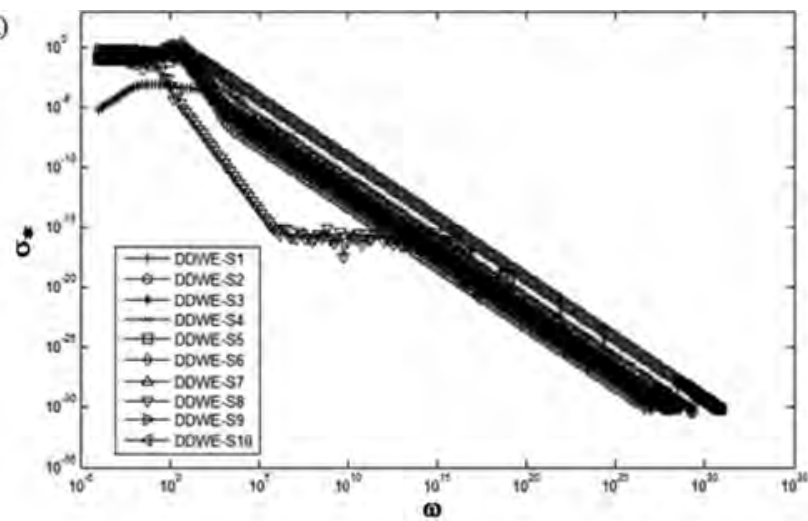

(b)

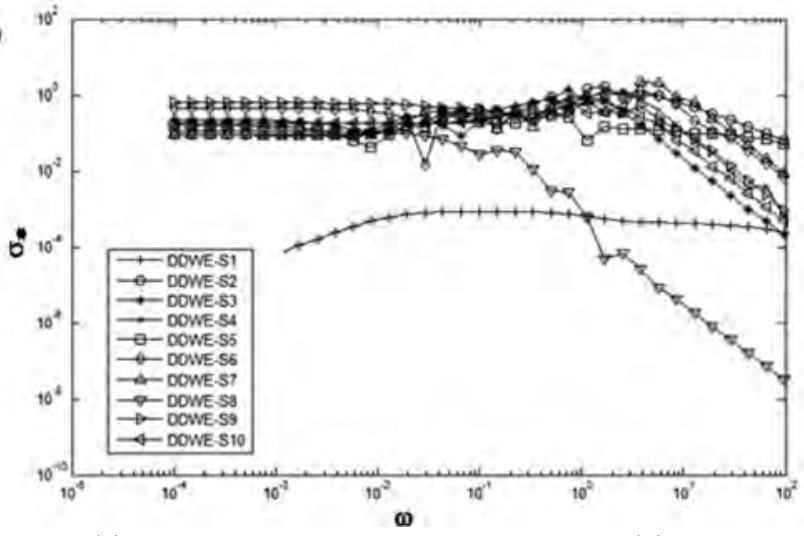

Figure 9. (a) Minimum singular value for DDWC, M2; (b) zoom-in to the low frequency region. 


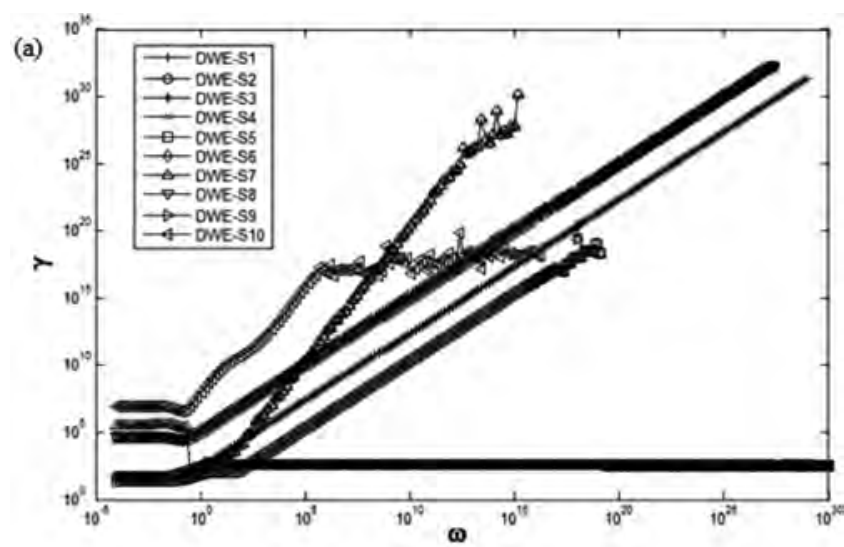

(b)

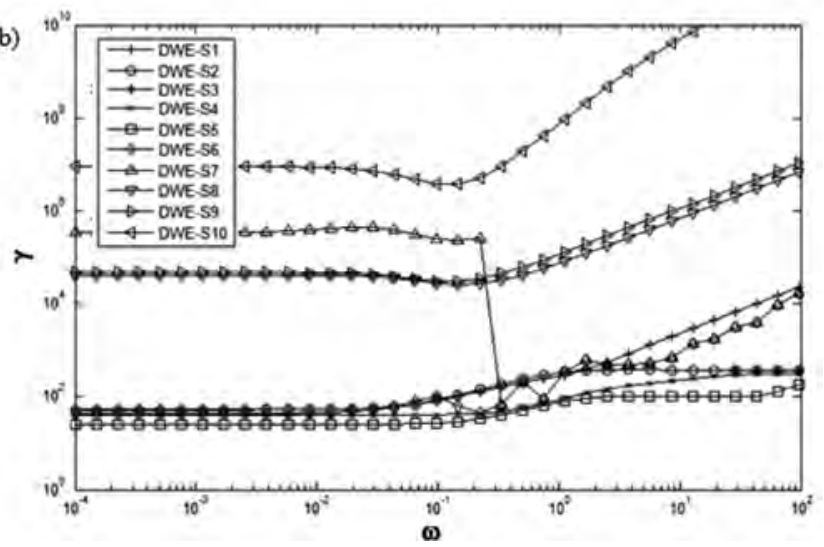

Figure 10. (a) Condition number for DWC, M2; (b) zoom-in to the low frequency region.

respectively, when separating mixture M1. In Tables 3 and 4, $R$ represents a perturbation in reflux ratio, $S$ a disturbance in side stream flow rate, and $Q$ a perturbation in heat duty; while NC5, NC6, and NC7 stand for $n$-pentane, $n$-hexane, and $n$-heptane, respectively. The minimum singular value for a wide range of frequency is shown in Figure 3a for the separation of M1 in a DWC. Since the values of $\sigma_{*}$ are quite similar for the different optimum designs obtained from the Pareto front, a zoom to the region of low frequency is presented in Figure 3b. In Figure 4, minimum singular values for the separation of M1 with a DDWC are presented. It can be seen that, for DWC, the values of $\sigma_{*}$ for the design $\mathrm{S} 1$ differ considerably from the minimum singular values for the other DWC designs. This does not occur with the DDWC, with most of the trajectories for $\sigma_{*}$ being considerably similar. For the DWC, the cases S2, S5, and S6 show the highest minimum singular number for almost all the low frequency region. It is important to observe that design S2 has the lowest heat duty for the DWC analyzed cases for mixture M1. For DDWC, the case with the highest number of condition is S5, which also corresponds to the case with the lowest heat duty. In Figure 5, obtained values for condition number are presented for DWC, while in Figure 6 the values of $\gamma$ are shown for DDWC. A similar performance can be observed for the condition number of DWC and DDWC at low frequencies. For a better comparison, values of $\sigma_{*}$ and $\gamma$ are presented in Figure 7 for the first five designs of DWC and the first five designs of DDWC. It can be seen that the design DWE-S1 has a considerably low minimum singular value and a high condition number when compared to the other designs; thus, this is the worst alternative in terms of dynamic properties. Most of the other designs present
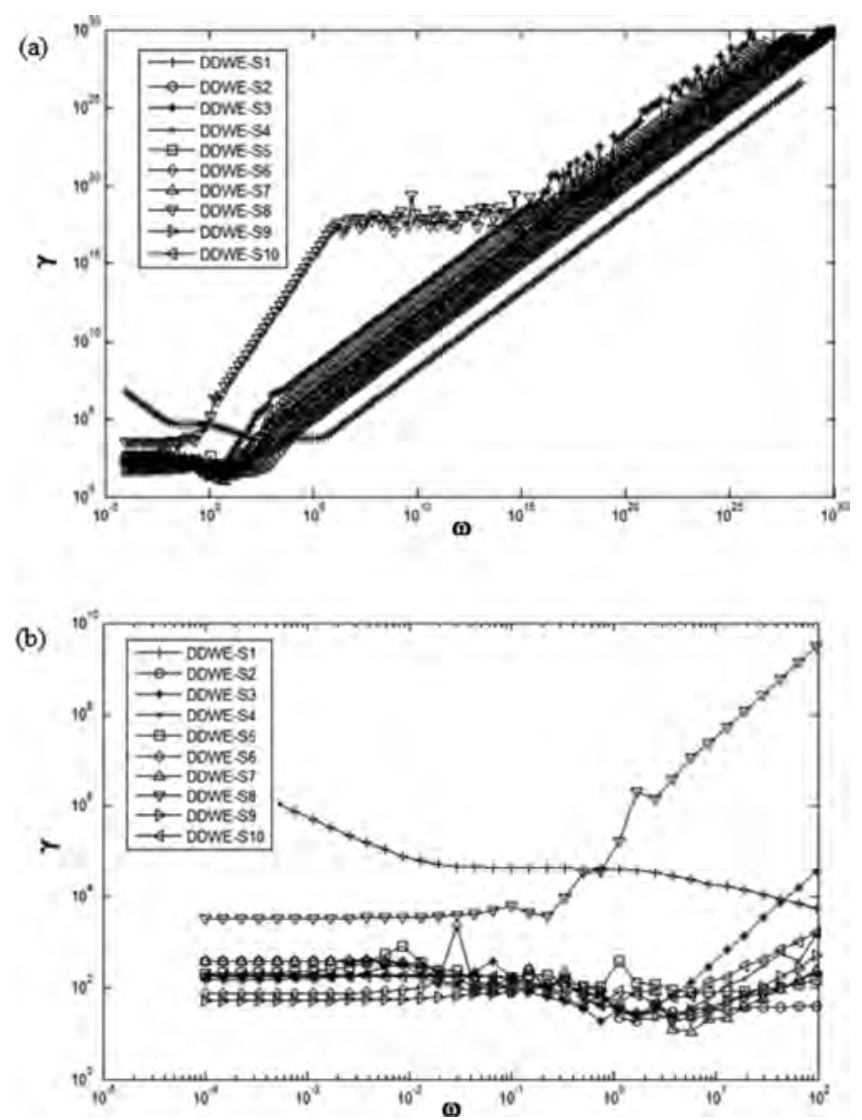

Figure 11. (a) Condition number for DDWC, M2; (b) zoom-in to the low frequency region.

similar dynamic properties at low frequencies, but when frequency becomes higher, an important increase in condition number can be observed for DWC systems, which does not occur with the DDWC schemes.

Now results of mixture M2 will be discussed. In Figure 8 values of $\sigma_{*}$ are presented for the designs of DWC systems. In Figure 9 values of minimum singular values are shown for DDWC. From Figure 8, it can be seen that, for the mixture with a high composition of the middle-boiling component, the last cases for DWC show low values of $\sigma_{*}$, and the case with the lowest heat duty has values of $\sigma_{*}$ in the middle region of the plot. Cases S4, $\mathrm{S} 5$, and $\mathrm{S} 6$ show the highest minimum singular values, with those designs having intermediate values for heat duty. For DDWC, it can be observed that design $S 1$ presents the lowest values for $\sigma_{*}$ at the region of low frequencies, while designs S9 and S6 have the highest minimum singular values. In Figures 10 and 11 the condition number is shown for DWC and DDWC, respectively. Similar trends to those observed for $\sigma_{*}$ occur for condition number. The last designs of DWC show the highest condition number, and the DDWC design with the lowest heat duty presents high condition numbers at low frequencies. Finally, in Figure 12 a comparison between the first five designs in the Pareto front is presented for DWC and DDWC. It can be seen that the designs with better dynamic properties correspond to DWC systems, in particular to the cases S4 and S5.

From the results obtained, it can be seen that, for the separation of mixtures with low feed composition of the middleboiling component, the DDWC shows the lowest energy requirements and better open-loop properties (and thus, potential for a better controllability) than the DWC. Furthermore, for that 


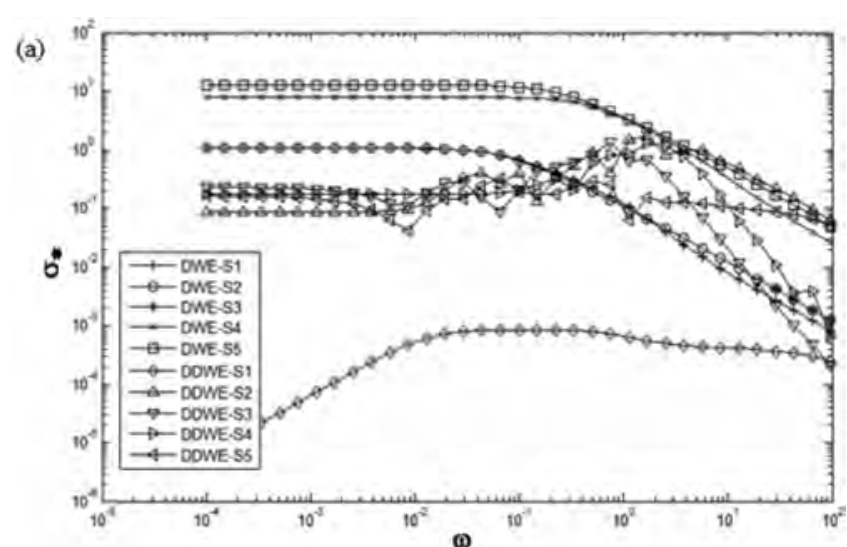

(b)

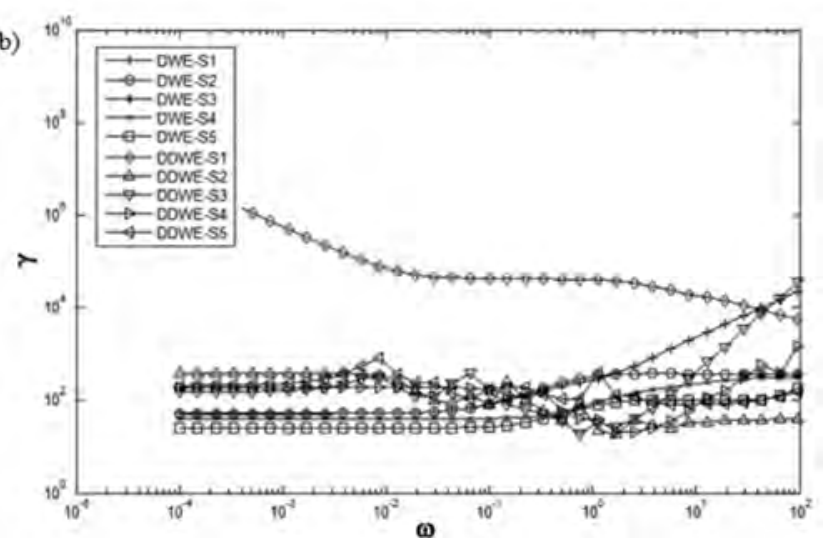

Figure 12. Comparison between dynamic properties of DWC and DDWC (M2): (a) minimum singular value; (b) condition number.

mixture it has been observed that the DDWC design with the lowest heat duty from the Pareto front has the better dynamic properties. For a mixture with a high feed composition of the middle-boiling component, it has been observed that the DWC shows the lowest energy requirements and better dynamic properties than the DDWC. Particularly, the DWC designs with an intermediate heat duty show the better open-loop properties.

\section{CONCLUSIONS}

Dynamic properties for distillation columns with one and two dividing walls have been studied. The effect of the feed composition on the open-loop properties has been analyzed. For a mixture with a low composition of the middle-boiling component, it has been observed that minimum singular values and condition numbers follow a similar performance in the low frequency region for both DWC and DDWC systems. Nevertheless, for a high frequency region, DDWC shows better open-loop parameters. Thus, for this mixture DDWC appears to be the best alternative in terms of open-loop properties and energy requirements. In the case of the mixture with high composition of the middle-boiling component, the opposite occurs, and the DWC is the best alternative in terms of open-loop properties and also in terms of energy requirements.

\section{AUTHOR INFORMATION}

\section{Corresponding Author}

*E-mail: fgomez@ugto.mx. Phone: (52) 4737320006 ext 8142.

Notes

The authors declare no competing financial interest.

\section{ACKNOWLEDGMENTS}

The authors acknowledge the financial support of CONACYT and Universidad de Guanajuato, Mexico.

\section{NOMENCLATURE}

$\mathbf{V}=$ matrix of left singular vectors

$\mathbf{W}^{\mathrm{H}}=$ matrix of right singular vectors

$\boldsymbol{\Sigma}$ = matrix of singular values

\section{Greek Symbols}

$\sigma_{*}[]$ minimum singular value

$\sigma^{*}[]$ maximum singular value

$\gamma[]$ condition number

\section{REFERENCES}

(1) Smith, R. Chemical Process Design and Integration, 2nd ed.; John Wiley \& Sons: West Sussex, U.K., 2005.

(2) Petlyuk, F. B.; Platonov, V. M.; Slavinskii, D. M. Thermodynamically optimal method for separating multicomponent mixtures. Int. Chem. Eng. 1965, 5, 555.

(3) Stupin, W. J.; Lockhart, F. J. Thermally coupled distillation-A case history. Chem. Eng. Prog. 1972, 68, 71.

(4) Glinos, K.; Malone, M. F. Optimality regions for complex column alternatives in distillation systems. Chem. Eng. Res. Des. 1988, 66, 229.

(5) Triantafyllou, C.; Smith, R. The design and optimization of fully thermally coupled distillation columns. Trans. IChemE 1992, 70, 118.

(6) Tedder, D. W.; Rudd, D. F. Parametric studies in industrial distillation: Part I. Design comparisons. AIChE J. 1978, 24, 303.

(7) Dünnebier, G.; Pantelides, C. C. Optimal design of thermally coupled distillation columns. Ind. Eng. Chem. Res. 1999, 38, 162 DOI: $10.1021 / \mathrm{ie} 9802919$.

(8) Hernández, S.; Jiménez, A. Design of energy-efficient Petlyuk systems. Comput. Chem. Eng. 1999, 23, 1005.

(9) Schultz, M. A.; Stewart, D. G.; Harris, J. M.; Rosenblum, S. P.; Shakur, M. S.; O'Brien, D. E. Reduce costs with dividing-wall columns. Chem. Eng. Prog. 2002, 98, 64.

(10) Lestak, F.; Smith, R.; Dhole, V. R. Heat transfer across the wall of dividing wall columns. Trans. IChemE 1994, 72, 639.

(11) Amminudin, K. A.; Smith, R.; Thong, D. Y. C.; Towler, G. P. Design and optimization of fully thermally coupled distillation columns. Part 1: Preliminary design and Optimization Methodology. Chem. Eng. Res. Des. 2001, 79, 701.

(12) Dejanovic, I.; Matijasevic, Lj.; Olujic, Z. Dividing wall column-A breakthrough towards sustainable distilling. Chem. Eng. Process. 2010, 49, 559.

(13) Kim, Y. H. A new fully thermally coupled distillation column with postfractionator. Chem. Eng. Process. 2006, 45, 254.

(14) Gómez-Castro, F. I.; Segovia-Hernández, J. G.; Hernández, S.; Gutiérrez-Antonio, C.; Briones-Ramírez, A. Dividing wall distillation columns: Optimization and control properties. Chem. Eng. Technol. 2008, 31, 1246.

(15) Gómez-Castro, F. I.; Rodríguez-Ángeles, M. A.; SegoviaHernández, J. G.; Gutiérrez-Antonio, C.; Briones-Ramírez, A. Optimal designs of multiple dividing wall columns. Chem. Eng. Technol. 2011, 34, 2051.

(16) Ruiz-Marín, L. E.; Ramírez-Corona, N.; Castro-Agüero, A.; Jiménez-Gutiérrez, A. Shortcut design of fully thermally coupled distillation systems with postfractionator. Ind. Eng. Chem. Res. 2011, 50, 6287.

(17) Olujic, Z.; Dejanovic, I.; Kaibel, B.; Jansen, H. Dimensioning multipartition dividing wall columns. Chem. Eng. Technol. 2012, 35, 1392.

(18) Wolff, E. A.; Skogestad, S. Operation of integrated three-product (Petlyuk) distillation columns. Ind. Eng. Chem. Res. 1995, 34, 2094.

(19) Abdul-Mutalib, M. I.; Smith, R. Operation and control of dividing wall distillation columns. Part I: Degrees of freedom and dynamic simulation. Trans. Inst. Chem. Eng. 1998, 76, 308. 
(20) Hernández, S.; Jiménez, A. Controllability analysis of thermally coupled distillation systems. Ind. Eng. Chem. Res. 1999, 38, 3957.

(21) Segovia-Hernández, J. G.; Hernández, S.; Rico-Ramírez, V.; Jiménez, A. Comparison of the feedback control behavior between thermally coupled and conventional distillation schemes. Comput. Chem. Eng. 2004, 28, 811.

(22) Halvorsen, I. J.; Skogestad, S. Optimizing control of Petlyuk distillation: Understanding the steady-state behavior. Comput. Chem. Eng. 1997, 21, S249.

(23) Serra, M.; Espuña, A.; Puigjaner, L. Control and optimization of the divided wall column. Chem. Eng. Process. 1999, 38, 549.

(24) Wang, S. J.; Wong, D. J. Controllability and energy efficiency of a high-purity divided wall column. Chem. Eng. Sci. 2007, 62, 1010.

(25) Ling, H.; Luyben, W. L. New control structure for divided wall columns. Ind. Eng. Chem. Res. 2009, 48, 6034.

(26) Ling, H.; Luyben, W. L. Temperature control of the BTX dividedwall column. Ind. Eng. Chem. Res. 2010, 49, 189.

(27) Kiss, A. A.; Bildea, C. S. A control perspective on process intensification in dividing-wall columns. Chem. Eng. Process. 2011, 50, 281.

(28) Buck, C.; Hiller, C.; Fieg, G. Applying model predictive control to dividing wall columns. Chem. Eng. Technol. 2011, 34, 663.

(29) Ignat, R, Woinaroschy, A. Dynamic analysis and controllability of dividing-wall distillation columns using a four points control structure. Sci. Bull.—Univ. "Politeh." Bucharest, Ser. B 2011, 73, 71.

(30) Kiss, A. A.; Rewagad, R. R. Energy efficient control of a BTX dividing wall column. Comput. Chem. Eng. 2011, 35, 2896.

(31) Dwivedi, D.; Strandberg, J. P.; Halvorsen, I. J.; Preisig, H. A.; Skogestad, S. Active vapor split control for dividing wall colums. Ind. Eng. Chem. Res. 2012, 51, 15176.

(32) van Diggelen, R. C.; Kiss, A. A.; Heemink, A. W. Comparison of control strategies for dividing-wall columns. Ind. Eng. Chem. Res. 2010, 49, 288.

(33) Niggemann, G.; Hiller, C.; Fieg, G. Modeling and in-depth analysis of the start-up of dividing wall columns. Chem. Eng. Sci. 2011, 66, 5268 .

(34) Rewagad, R. R.; Kiss, A. A. Dynamic optimization of a dividingwall column using model predictive control. Chem. Eng. Sci. 2012, 68, 132.

(35) Martinez-Cisneros, J.; Hernández-Sánchez, A. A.; SegoviaHernández, J. G.; Hernández, S.; Hernández, H. Dynamic behavior of alternate scheme to Petlyuk column (dividing wall column) for separation of ternary mixtures. Rev. Mex. Ing. Quim. 2009, 8, 135. 